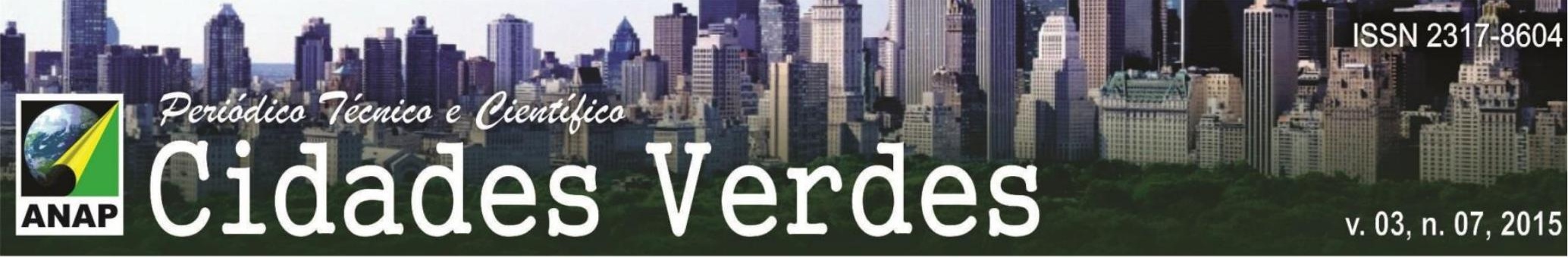

\title{
BAIRROS SUSTENTÁVEIS: DESENHOS E PRÁTICAS EM DISCUSSÃO
}

\author{
Samara Veríssimo Chaves Guimarães ${ }^{1}$
}

Eloisa Carvalho de Araujo ${ }^{2}$

Diogo Ubaldo Braga ${ }^{3}$

\begin{abstract}
RESUMO
O presente artigo tem o intuito de apresentar experiências de projetos de bairros sustentáveis em grandes cidades internacionais. A partir de um método comparativo dos estudos de caso internacionais, diretrizes puderam ser extraídas para serem incorporadas, eventualmente, aos casos brasileiros. Também o artigo propicia, considerando reflexão sobre abordagem do conceito de sustentabilidade, variações possíveis de um ambiente construído sustentável. Essas contribuições, segundo os autores, a partir de uma visão transdisciplinar, podem fomentar a promoção do intercâmbio de experiências, discussões e debates sobre a temática da sustentabilidade nas cidades contemporâneas.
\end{abstract}

PALAVRAS-CHAVE: Urbanismo. Sustentabilidade. Bairros.

\section{SUSTAINABLE NEIGHBORHOODS: DRAWINGS AND PRACTICE IN DISCUSSION}

\footnotetext{
${ }^{1}$ Mestranda do Programa de Pós-Graduação em Arquitetura e Urbanismo da Universidade Federal Fluminense. Graduada em Arquitetura e Urbanismo. samaravcg@hotmail.com

${ }^{2}$ Doutora em Urbanismo. Mestre em Geografia. Graduada em Arquitetura e Urbanismo. Professora do Programa de Pós-Graduação em Arquitetura e Urbanismo da Universidade Federal Fluminense. eloisa.araujo@gmail.com

${ }^{3}$ Graduado em Arquitetura e Urbanismo pela Universidade Federal Fluminense. Graduado em Direito.diogoubaldobraga@yahoo.com.br
} 


\begin{abstract}
This article aims to introduce sustainable neighborhood project experiences in large international cities. From a comparative method of international case studies, guidelines could be extracted to be merged eventually to Brazilian cases. The article also provides considering reflection on the concept of sustainability approach, possible variations of a sustainable built environment. These contributions, according to the authors, from a transdisciplinary vision, can foster the promotion of exchange of experiences, discussions and debates on the topic of sustainability in contemporary cities.
\end{abstract}

KEY WORDS: Urbanism. Sustainability. Neighborhoods.

\title{
BARRIOS SOSTENIBLES: DIBUJOS Y PRÁCTICA EN DISCUSIÓN
}

\section{RESUMEN}

En este artículo se pretende introducir la experiencia sostenible proyecto de barrio en las grandes ciudades internacionales. A partir de un método comparativo de estudios de casos internacionales, directrices podrían ser extraídos para ser fusionado con el tiempo a los casos de Brasil. Artículo también proporciona considerando la reflexión sobre el concepto de enfoque de sostenibilidad, posibles variaciones de un entorno construido sostenible. Estas contribuciones, según los autores, a partir de una visión transdisciplinaria, pueden fomentar la promoción del intercambio de experiencias, discusiones y debates sobre el tema de la sostenibilidad en las ciudades contemporáneas.

PALABRAS CLAVES: Urbanismo. Sostenibilidad. Barrios.

\section{INTRODUÇÃO}

$\mathrm{Na}$ segunda metade do século passado a discussão ambiental criou relevância no cenário internacional e desde a publicação do livro "Limites do Crescimento", em 1972, pelo Clube de Roma, até os dias de hoje muitos fóruns e encontros internacionais foram realizados com o intuito de discutir o conceito. $\mathrm{Na}$ atualidade, muito já se discutiu e muito já foi divulgado sobre Sustentabilidade.

Apesar disto, o conceito de sustentabilidade ainda é matéria controversa e quando analisado de forma isolada pode abrir margem para uma infinidade de interpretações que irão variar de acordo com o lugar, o contexto e a bagagem cultural de cada indivíduo. Sustentabilidade, pelo dicionário Silveira Bueno é "o que 
se pode sustentar" ${ }^{4}$. Assim sendo, uma empresa que se sustenta ativa no mercado financeiro por longo período de tempo, pode-se dizer sustentável. E um empreendimento que, a partir de uma articulação de capital fundiário, financeiro e imobiliário, e respeitando condicionantes físicos e sociais tem grandes possibilidades de ser considerado sustentável.

No entanto, não é, por certo, pelo conceito de sustentabilidade que os políticos discursam, os cientistas pesquisam e os Estados apoiam suas discussões, é sim pela expressão "desenvolvimento sustentável". Esta expressão une a concepção de desenvolvimento econômico à preocupação ecológica e segundo inúmeros autores, incluindo SASSI (2006), foi consolidada em 1987 no relatório chamado "Our Common Future" elaborado pela Comissão Mundial de Meio Ambiente e Desenvolvimento das Nações Unidas ${ }^{5}$, para debate na $42^{a}$ Sessão da Assembleia Geral das Nações Unidas. Tal definição apresenta-se como aquela que "satisfaz as necessidades presentes, sem comprometer a capacidade das gerações futuras de suprir suas próprias necessidades" ${ }^{6}$ (United Nations, 1987). O relatório ressalta o fato de que o empobrecimento da maioria da população é uma das principais causas dos problemas ambientais em escala planetária.

ACSELRAD (2011) articula que diferentes valores e representações vêm sendo associados à noção de sustentabilidade. São discursos em disputa pela expressão que se pretende a mais legitima, porque esta é uma noção que se pode recorrer para tornar objetivas diferentes representações e ideias. O autor destaca quatro matrizes discursivas que veem sendo associadas à noção de sustentabilidade: a matriz da eficiência, da equidade, da autossuficiência e da ética.

Nos anos seguintes à concepção do relatório "Our Common Future", por volta do final do século passado e início deste, que surgiu a maioria dos ministérios

\footnotetext{
${ }^{4}$ BUENO, Silveira. Minidicionário da Língua Portuguesa. São Paulo: Maria Cecília Mendes de Almeida, 2000, p.739.

${ }^{5}$ A Comissão Mundial de Meio Ambiente e Desenvolvimento das Nações Unidas era, à época, chefiada pela primeira ministra da Noruega, Gro Harlem Brundtland.

${ }^{6}$ Trecho do Relatório Nosso Futuro Comum, Bruntland, 1987 também citado em: SASSI, Paola. Strategies for Sustainable Architecture. Abingdon: Taylor \& Francis, 2006, p. 2 e LEITE, Carlos; AWAD, Juliana di Cesare Marques. Cidades Sustentáveis, Cidades Inteligentes: Desenvolvimento Sustentável num Planeta Urbano. Porto Alegre: Bookman, 2012, p. 29.
} 
do meio ambiente, secretarias e comissões que sempre procuram adicionar em sua nomenclatura o termo sustentabilidade.

Já no âmbito privado existem inúmeras empresas que procuram associar o seu produto à causa sustentável e da preservação ambiental. São bancos, jogos, produtos alimentícios que se utilizam do termo como uma estratégia de Marketing. Fato é que o conceito de sustentabilidade é carregado de forte apelo ético e é interesse dessas empresas associarem seus produtos a esta causa.

No entanto, enquanto a popularização da palavra sustentabilidade tem uma face positiva, esconde também uma negativa. Isto porque, a apropriação deste conceito pelo marketing empresarial quase sempre é tendenciosa. Além disso, a abordagem do conceito de sustentabilidade se dá sempre de forma superficial, visto que o objetivo é a venda de determinado produto. O termo "cidades verdes" pode vir a se configurar também como uma possível alternativa à utilização do conceito de cidades sustentáveis.

\section{OBJETIVOS}

Nesse sentido, a fim de aprofundar a reflexão e a percepção do conceito do termo sustentabilidade quando aplicado ao ambiente urbano, propomos trazer o tema novamente para discussão, e, amparados em pesquisa em curso no campo da infraestrutura e cidade: relações entre espaço e meio ambiente ${ }^{7}$.

Inicialmente, através de uma revisão bibliográfica, propusemos tanto resgatar contribuições no campo teórico, como apontar e debater questões sobre desenho urbano e práticas adotadas em experiências de bairros internacionais, pautados no urbanismo sustentável, a fim de, eventualmente, poderem influenciar intervenções no ambiente urbano das cidades brasileiras. Com isto, desejamos levantar questões e incentivar tanto a investigação teórica como as práticas, a partir de desenhos de bairros que se dizem sustentáveis.

\footnotetext{
${ }^{7}$ Esta pesquisa integra o Grupo de Pesquisa do CNPq - Cidade, Processos de Urbanização e Ambiente.
} 
E, por fim, pretendemos que esse artigo possa contribuir para a difusão e socialização do conhecimento a partir de uma visão transdisciplinar, visando o intercâmbio de experiências, discussões e debates sobre a temática da sustentabilidade nas cidades contemporâneas.

\section{METODOLOGIA}

O primeiro momento da pesquisa foi dedicado à compreensão do objeto de estudo, realizada a partir de levantamento de aportes teóricos sobre urbanismo e bairros sustentáveis. Em sequência, a definição de estudos de caso internacionais conhecidos, dos quais pudessem ser extraídas diretrizes a serem incorporadas, eventualmente, aos casos brasileiros.

$\mathrm{Na}$ tentativa de entender o viés das intervenções sustentáveis no âmbito urbano europeu, o estudo foi procedido adotando o método comparativo a partir de aspectos de um ambiente construído sustentável para a análise dos casos. Tal comparação foi construída a partir de base teórica, utilizando como ponto de partida contribuições de JENKS E COLIN (2010) em seu livro "Dimensions of the Sustainable City" ${ }^{\text {". }}$ Para os autores, a forma urbana sustentável é uma questão complexa e suas dimensões físicas têm que incluir o tamanho, formato, uso do solo, configuração e distribuição de espaços abertos, embora a sustentabilidade do espaço dependa de outras questões mais abstratas, como as dimensões ambiental (incluindo transporte), social e econômica. A abordagem de JENKS E COLIN (2010) sobre o ambiente sustentável se divide em quatro aspectos, quais sejam: "uso do solo e morfologia", "conservação de energia", "reciclagem e re-uso" e "comunicação e transporte". Todavia, os estudos efetuados pelo referido autor se dão em âmbito Europeu, possuindo uma realidade distinta do Brasil. E, nesse caso, nosso contexto demandou a necessária inclusão do aspecto do "Direito à Cidade", e, a "Questão Ambiental" como um novo grupo que passa assim a incorporar os temas de conservação de energia e reciclagem e re-uso, para dar conta dos aspectos ambientais.

\footnotetext{
${ }^{8}$ JENKS, Mike; COLIN, Jenks. Dimensions of the Sustainable City. New York: SPRINGER, 2010.
} 
Esta nova forma de abordar, nos permitiu também, debruçar sobre os casos e dar um enfoque social à análise. Além disso, buscamos trazer para a análise os 27 princípios da Carta do Novo Urbanismo Americano ${ }^{9}$, com atenção para os sistemas de transportes, de infraestrutura sanitária, associados aos conceitos de compacidade $^{10}$ do espaço urbano e do projeto da paisagem como um todo.

Esta iniciativa, ainda em desenvolvimento, nos possibilita, através desse método, articulado ao conceito de sustentabilidade, uma análise mais profunda sobre os casos escolhidos, que transpassa os slogans verdes e o marketing, incorporando, além dos aspectos ambientais, características sociais e de vivência do espaço.

Foram escolhidos cinco exemplos para uma análise quanto à definição e conteúdo do que seria um bairro sustentável, dos quais; bairro de Burgholzhof, da cidade de Stuttgart na Alemanha, o bairro de Reiselfeld na cidade de Freiburg na Alemanha, o bairro de Vauban em Berlim na Alemanha, o bairro GWL em Amsterdã na Holanda e o bairro de Viikki em Helsinque na Finlândia.

A análise foi feita com o objetivo de entender qual o viés predominante das tais cidades sustentáveis, considerando três grandes grupos em que se enquadrariam as intervenções realizadas nestes meios urbanos: a dimensão social, econômica e ambiental. Por fim, com base na análise dos estudos de casos internacionais e do estudo bibliográfico, realizaremos um quadro com diretrizes de desenho e práticas sustentáveis a serem incorporadas aos casos brasileiros.

\section{RESULTADOS}

\footnotetext{
${ }^{9}$ A Carta do Novo Urbanismo estabelece princípios associados à formação do espaço regional, da cidade, e do bairro, focando três eixos básicos: Planejamento urbano e regional, qualidade dos projetos locais e participação das comunidades. Ver em: ftp://ftp.usjt.br/pub/revint/11_48.pdf - A Carta do Novo Urbanismo. Acesso em: 02 de abril de 2015.

${ }_{10}$ Conceito abordado por Rodrigo Argenton Freire, Dissertação de Mestrado na Faculdade de Engenharia Civil, Arquitetura e Urbanismo (FEC) da Unicamp, 2014, ressalta que cidades compactas propiciam sustentabilidade urbana e aumentam as interações humanas. Seu estudo buscou evidenciar a relação existente entre as dimensões de compacidade, através da densidade populacional e diversidade - social e de usos - e a forma urbana. Ver em: http://www.unicamp.br/unicamp/ju/610/compacidade. Acesso em: 04 de junho de 2015.
} 
Para FARR (2013), reafirmar a definição do termo "bairro" se tornou necessária, já que não se utiliza mais essa palavra para se referir aos empreendimentos desconectados, de uso único, característicos da urbanização dispersa. Os parâmetros do bairro ideal não são específicos, já que estes devem ser variados para refletir os costumes regionais, o clima e as condições dos terrenos, embora existam cinco convenções básicas de desenho urbano que conferem um caráter comum aos grandes bairros: centro facilmente identificável, com pelo menos um ambiente público ao ar livre, que estimule a reunião de pessoas; tamanho ideal para o pedestre, sendo o raio de 400 metros um parâmetro para criação de unidades de vizinhança e incentivando a locomoção a pé ou de bicicleta; composição diversa de usos do solo e tipos de habitação com oportunidades para comércio e locais de trabalho próximos das moradias; rede integrada de vias orientadas para o pedestre, proporcionando segurança e conforto; e terrenos especiais reservados para propósitos comunitários, sejam edificações cívicas ou parques, áreas verdes, praças e parques infantis.

O que FARR (2013) destaca como convenções básicas de desenho urbano para um bairro ideal encontra correspondência nos princípios elencados na carta do Novo Urbanismo Americano, que constantemente são atribuídos como medidas sustentáveis. Como por exemplo:

\begin{abstract}
Princípio 11 - "Bairros devem ser compactos, amigáveis aos pedestres e de uso misto. Distritos geralmente enfatizam um único uso especial e deveriam seguir os princípios de projetos de bairro, quando possível.Corredores são conectores regionais dos bairros e distritos; eles variam de avenidas e linhas ferroviárias, para rios e vias arborizadas".

Princípio 13 - "Nos bairros, uma ampla gama de tipos de habitação e preços pode atrair pessoas de diversas idades, raças e níveis de renda facilitanto a interação diária e fortalecendo os laços pessoais e cívicos, essenciais para uma autêntica comunidade". Princípio 18 - "Uma variedade de parques, desde parques infantis e espaços verdes, a campos desportivos e jardins comunitários, deve ser distribuída nos bairros. Áreas de conservação e espaços abertos devem ser usados para definir e conectar diferentes bairros e distritos". (LECCESE, M. \& McCORMICK, K, 2000). ${ }^{11}$
\end{abstract}

\footnotetext{
${ }^{11}$ LECCESE, M. \& MCCORMICK, K. Charter of the New Urbanism. Congress for the New Urbanism. Nova York: McGraw-Hill, 2000. Disponível em: http://www.cnu.org/charter. Acesso em: 05 de junho de 2015. Tradução dos autores.
} 
Nos princípios 11, 13 e 18 da carta do Novo Urbanismo Americano podemos observar claramente as convenções básicas de desenho urbano que FARR (2013) advoga para a criação de um bairro ideal. Já nos casos de cidades Europeias que iremos analisar, iremos, possivelmente, identificar muitas dessas convenções, isto ocorre porque a urbanização na Europa se encontra muito atrelada com sua tradição da cidade medieval que produz ambientes urbanos muito mais compactos que a cidade espraiada americana.

Procedendo à análise dos casos, o bairro de Burgholzhof se localiza a nordeste da cidade de Stuttgart, Alemanha. Era o local das antigas instalações do exército americano. O bairro contém: diversidade social na habitação, com 600 apartamentos nos imóveis do setor privado, 60 habitações econômicas com possibilidade de acesso à propriedade por parte de jovens famílias, 195 moradias para os funcionários do Hospital Robert-Bosch; utilização de energia solar para produção de água quente; projetos arquitetônicos de edifícios de modo a otimizar a captação da energia solar; alimentação de energia dos edifícios por uma central urbana de aquecimento de gás; obrigatoriedade de construir imóveis que atendessem às exigências do selo Habitação de Baixa Energia; coberturas com vegetação; áreas de estacionamento gramadas e número mínimo de árvores definido para cada lote; priorização do pedestre e limitação da velocidade dos carros. 


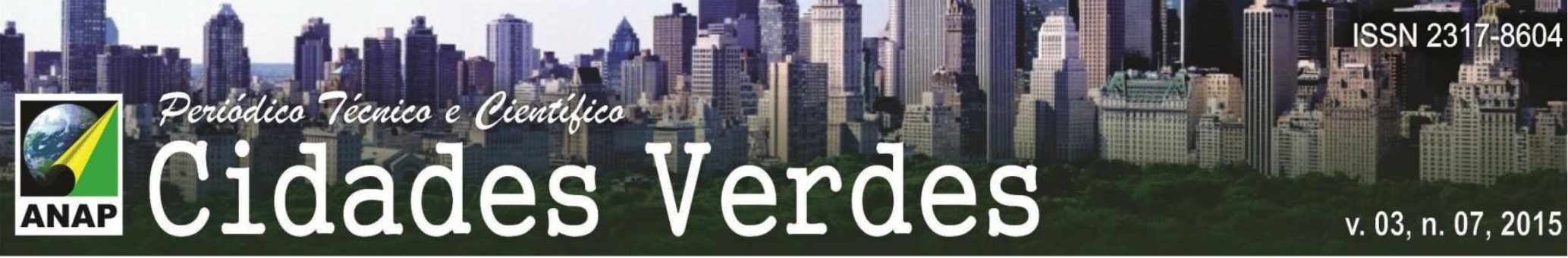

pluviais no próprio lote; exigência do selo Habitação de Baixa Energia; incentivo de uso de transportes alternativos aos automóveis; diálogo e instrução entre prefeitura e população; equipamentos públicos de qualidade arquitetônicos e pautados no princípio de sustentabilidade.

Figura 2: Habitações no bairro de Vauban, Freiburg.

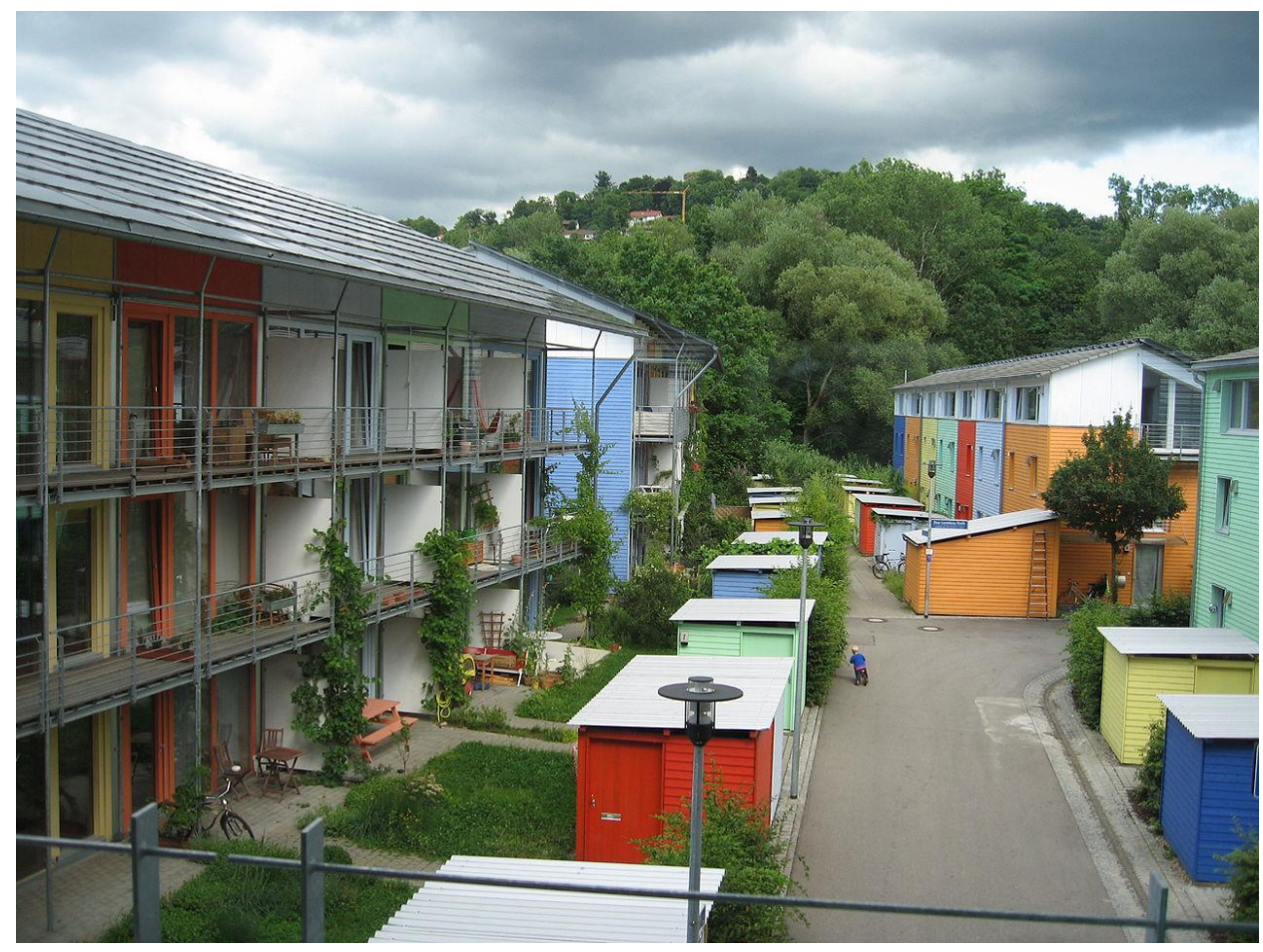

Fonte: http://en.wikipedia.org/wiki/File:Écoquartier_vauban_freibourg1.JPG. Acesso em: 05/06/2015

Bairro GWL se localiza na cidade de Amsterdã, Holanda. O bairro contém: incorporação de uma lista de materiais alternativos e ecológicos às "Exigências e recomendações para as novas construções", de 1992; política restritiva para a circulação de automóveis e para o estacionamento no centro da cidade; grandes obras de infraestrutura para a melhoria dos transportes coletivos, principalmente 0 metrô; ampliação da rede de ciclovias; reestruturação de terrenos abandonados; reformas das habitações e dos equipamentos públicos na orla marítima; melhoria da paisagem e das áreas de lazer; grande densidade no centro bem definido, permitindo áreas mais abertas no restante do bairro; velocidade de tráfego reduzida 
e calçadas; unidades de compostagens públicas, coleta seletiva, calçamento com alta taxa de permeabilização e tanques de retenção das águas pluviais; eliminação total dos automóveis em certas localidades.

O bairro de Viikki, Helsinque, Finlândia. O bairro contém: estabelecimento de cinturões verdes e corredores verdes com áreas para caminhadas; programa de economia de energia para o setor imobiliário da cidade. $91 \%$ das habitações e 95\% dos escritórios estão ligados à rede pública de aquecimento; adensamento urbano; programa de proteção à natureza e gestão ecológica das florestas. 10m2 de jardins municipais por habitante; expansão do uso dos transportes públicos; ampliação da rede cicloviária $(850 \mathrm{~km}$ de ciclovias); estímulo à diversidade social dos novos empreendimentos; equilíbrio entre a moradia e o emprego no bairro; elaboração de uma agenda 21 local; construção de equipamentos públicos de arquitetura de qualidade pautada no princípio da sustentabilidade.

No caso dos bairros Burgholzhof e Vauban, ambos na Alemanha, dão uma importância maior aos aspectos do ambiente construído relativos às questões ambientais, embora também contemplem os outros três aspectos. Os bairros Reiselfeld, na Alemanha, e GWL, na Holanda, contemplam muito mais os aspectos relativos a uso do solo e morfologia, e comunicação e transporte, do que os aspectos ambientais. O caso que contempla igualmente os quatro aspectos é o Viikki, na Finlândia.

Embora os bairros tenham características diferentes entre si e deem um maior enfoque em um ou outro aspecto de um ambiente construído sustentável, todas as experiências abarcam as dimensões ambiental, social e econômica.

Em consonância com as definições de JENKS E COLIN (2010) para um ambiente construído sustentável, fizemos esforço de extrair dos casos estudados algumas contribuições para a elaboração de diretrizes/recomendações de desenho e práticas que possam nortear a construção de futuros bairros brasileiros, a serem pautados nos preceitos do urbanismo sustentável. Para isso foi construída uma adaptação da tabela proposta por JENKS E COLIN (2010), que seja condizente com a realidade brasileira. 


\section{Quadro 01: Aspectos de um Ambiente Construído Sustentável}

\begin{tabular}{|c|c|c|c|}
\hline $\begin{array}{l}\text { Uso do Solo e } \\
\text { Morfologia }\end{array}$ & Direito à Cidade & A Questão Ambiental & $\begin{array}{l}\text { Comunicação e } \\
\text { Transporte }\end{array}$ \\
\hline $\begin{array}{l}\text { Uso intensivo do solo } \\
\text { urbano }\end{array}$ & $\begin{array}{l}\text { Região metropolitana } \\
\text { bem definida }\end{array}$ & $\begin{array}{l}\text { Produção combinada } \\
\text { de calor e energia }\end{array}$ & $\begin{array}{l}\text { Rotas de trânsito leve, } \\
\text { ônibus eco-amigáveis e } \\
\text { ciclovias }\end{array}$ \\
\hline $\begin{array}{l}\text { Redes de corredores } \\
\text { verdes }\end{array}$ & $\begin{array}{l}\text { Planejamento físico e } \\
\text { estratégias econômicas } \\
\text { que englobem toda a } \\
\text { região metropolitana }\end{array}$ & $\begin{array}{c}\text { Sistema de captação de } \\
\text { águas cinzas }\end{array}$ & $\begin{array}{l}\text { Criação de "grupos de } \\
\text { carona" e revezamento } \\
\text { na utilização do } \\
\text { automóvel }\end{array}$ \\
\hline $\begin{array}{l}\text { Edifícios comunitários } \\
\text { autogeridos }\end{array}$ & $\begin{array}{l}\text { Respeito ao legado } \\
\text { histórico }\end{array}$ & $\begin{array}{l}\text { Micro geradores de } \\
\text { energia local }\end{array}$ & $\begin{array}{c}\text { Infraestrutura } \\
\text { estimulante para os } \\
\text { pedestres }\end{array}$ \\
\hline $\begin{array}{l}\text { A concentração de } \\
\text { atividades de interesse } \\
\text { público, institucionais e } \\
\text { comerciais deve ocorrer } \\
\text { nos bairros e nos } \\
\text { distritos, e não em um } \\
\text { conjunto específico } \\
\text { isolado e monofuncional }\end{array}$ & $\begin{array}{l}\text { Habitação de interesse } \\
\text { social deve ser } \\
\text { distribuída na região } \\
\text { para mesclar-se às } \\
\text { oportunidades de } \\
\text { emprego, evitando a } \\
\text { concentração da } \\
\text { pobreza }\end{array}$ & $\begin{array}{l}\text { Reuso de águas para } \\
\text { utilização em parques e } \\
\text { espaços verdes }\end{array}$ & $\begin{array}{l}\text { Muitas atividades do } \\
\text { cotidiano podem } \\
\text { acontecer a uma } \\
\text { distância possível de se } \\
\text { percorrer a pé, } \\
\text { possibilitando } \\
\text { independência àqueles } \\
\text { que não dirigem } \\
\text { veículos }\end{array}$ \\
\hline $\begin{array}{l}\text { Edifícios institucionais e } \\
\text { lugares públicos de } \\
\text { reunião requerem sítios } \\
\text { significativos para } \\
\text { reforçar sua identidade } \\
\text { e a cultura da } \\
\text { democracia }\end{array}$ & $\begin{array}{l}\text { Nos bairros, uma } \\
\text { grande variedade de } \\
\text { tipos de moradia e } \\
\text { preços para facilitar a } \\
\text { interação no dia-a-dia } \\
\text { de pessoas de diversas } \\
\text { idades, raças e níveis } \\
\text { de renda, reforçando os } \\
\text { vínculos pessoais e } \\
\text { cívicos, essenciais para } \\
\text { o crescimento de uma } \\
\text { autêntica comunidade }\end{array}$ & $\begin{array}{c}\text { Classificações } \\
\text { ecológicas excelentes } \\
\text { (como os selos } \\
\text { BREEAM, LEED, } \\
\text { AQUA) }\end{array}$ & $\begin{array}{l}\text { Conectividade entre a } \\
\text { malha viária existente } \\
\text { da região e as vias } \\
\text { projetadas do novo } \\
\text { empreendimento }\end{array}$ \\
\hline $\begin{array}{c}\text { Grande centro urbano } \\
\text { bem definido com a } \\
\text { presença de outros } \\
\text { centros de bairro } \\
\text { menores }\end{array}$ & $\begin{array}{l}\text { Locação de áreas } \\
\text { destinadas para a } \\
\text { construção de hospitais } \\
\text { e/ou clínicas dedicadas } \\
\text { ao atendimento e } \\
\text { acompanhamento } \\
\text { médico }\end{array}$ & $\begin{array}{l}\text { Altos níveis de } \\
\text { isolamento }\end{array}$ & $\begin{array}{l}\text { Estacionamentos com } \\
\text { restrições }\end{array}$ \\
\hline $\begin{array}{c}\text { Áreas de preservação e } \\
\text { áreas abertas usadas } \\
\text { para definir e conectar } \\
\text { diferentes bairros e } \\
\text { distritos }\end{array}$ & $\begin{array}{c}\text { Estabelecimento de } \\
\text { áreas públicas } \\
\text { destinadas a atividades } \\
\text { de lazer }\end{array}$ & $\begin{array}{c}\text { Iluminação inteligente e } \\
\text { sistemas de segurança, } \\
\text { aquecimento e } \\
\text { informação integrados }\end{array}$ & Sistema de informação \\
\hline
\end{tabular}




\begin{tabular}{|c|c|c|c|}
\hline $\begin{array}{l}\text { Uso do Solo e } \\
\text { Morfologia }\end{array}$ & Direito à Cidade & A Questão Ambiental & $\begin{array}{c}\text { Comunicação e } \\
\text { Transporte }\end{array}$ \\
\hline $\begin{array}{c}\text { Projeto flexível e } \\
\text { espaços de qualidade }\end{array}$ & $\begin{array}{c}\text { Conectividade física } \\
\text { entre os bairros, para } \\
\text { que as áreas de lazer, o } \\
\text { comércio e os } \\
\text { equipamentos públicos } \\
\text { possam ser } \\
\text { compartilhados }\end{array}$ & $\begin{array}{l}\text { Utilização de águas } \\
\text { recicladas para } \\
\text { jardinagem e lavagem } \\
\text { de carro }\end{array}$ & $\begin{array}{l}\text { Orientação ambiental. } \\
\text { Itinerário dos ônibus, } \\
\text { estado do trânsito e } \\
\text { monitoramento da } \\
\text { energia e água }\end{array}$ \\
\hline $\begin{array}{l}\text { Os bairros devem ser } \\
\text { compactos e devem ter } \\
\text { uso do solo do tipo } \\
\text { misto }\end{array}$ & $\begin{array}{l}\text { O desenho das ruas e } \\
\text { dos edifícios de forma a } \\
\text { reforçar a segurança } \\
\text { dos lugares, mas não } \\
\text { em prejuízo da } \\
\text { acessibilidade e sentido } \\
\text { de abertura }\end{array}$ & $\begin{array}{l}\text { Reciclagem de resíduos } \\
\text { para a produção de } \\
\text { biogás }\end{array}$ & \\
\hline $\begin{array}{l}\text { Uso de materiais } \\
\text { construtivos } \\
\text { sustentáveis }\end{array}$ & & $\begin{array}{c}\text { Redução do } \\
\text { desperdício doméstico } \\
\text { e na construção }\end{array}$ & \\
\hline $\begin{array}{l}\text { Moradias a preços } \\
\text { acessíveis }\end{array}$ & & $\begin{array}{l}\text { Devido tratamento do } \\
\text { esgoto sanitário }\end{array}$ & \\
\hline $\begin{array}{l}\text { Diversidade de usos em } \\
\text { áreas relativamente } \\
\text { densas }\end{array}$ & & $\begin{array}{c}\text { Redução do consumo } \\
\text { de energia }\end{array}$ & \\
\hline $\begin{array}{l}\text { Isolamento contra } \\
\text { ruídos }\end{array}$ & & $\begin{array}{l}\text { Estilo de vida carbono- } \\
\text { zero }\end{array}$ & \\
\hline Identidade Local & & Energia renovável & \\
\hline
\end{tabular}

Fonte: Tradução e adaptação dos autores sobre contribuições de JENKS, Mike; COLIN, Jenks.

Dimensions of the Sustainable City. New York: SPRINGER, 2010, p. 03.

\section{CONCLUSÃO}

Com o conhecimento e análise destes exemplos de bairros sustentáveis europeus, e pautados em aportes teóricos sobre o tema, sugerimos outros aspectos, que possam vir a integrar um ambiente construído sustentável. Aspectos que somados aos já propostos por JENKS E COLIN (2010) formam um quadro de diretrizes de desenho e práticas, que podem ser aplicados à realidade brasileira. A pertinência desses casos se dá por não serem exemplos extremos de arquitetura Hightech ou Lowtech $^{12}$, possuindo intervenções equilibradas e proporcionais à

${ }^{12}$ Hightech - trata-se de uma corrente da arquitetura, emergente nos anos 70, muito centrada no emprego de materiais de tecnologia avançada nas construções. Já o termo Lowtech está associado 
escala do bairro. Nem tampouco estes exemplos fizeram utilização de material publicitário exaustivo, o que indica uma maior preocupação com o efetivamente ser, em detrimento ao parecer ser. No entanto, a simples extração de aspectos de desenhos e práticas de exemplos de bairros sustentáveis europeus não é suficiente para a transposição à realidade brasileira. A estrutura original do quadro proposto por JENKS E COLIN (2010) foi adaptada para adicionar o aspecto "Direito à Cidade", enquanto a "Questão Ambiental" passou a incorporar as categorias "Conservação de energia" e "Reciclagem e re-uso".

Acreditamos que o desenvolvimento urbano sustentável, assim como LEITE (2012), idealizado a partir do Relatório Nosso Futuro Comum, impõe o desafio de refazer a cidade existente, de um modo inteligente e inclusivo, adaptando-a, sempre que possível, ao crescimento e às transformações econômicas, urbanísticas e culturais.

Portanto, a análise, acima apresentada, dos aspectos de sustentabilidade nos bairros europeus nos fez entender que as suas intervenções se dão normalmente de forma equilibrada e abarcando todas as dimensões da sustentabilidade: a ambiental, econômica e social. No entanto, em uma realidade brasileira, em que o desequilíbrio tende para os aspectos econômicos, de forma que a publicidade e o marketing da preservação ambiental muitas vezes é apenas estratégia para supervalorização de empreendimentos imobiliários e da imagem política das cidades, faz-se necessário a inversão da balança. No Brasil, a dimensão social da sustentabilidade tem sempre que estar evidente e ser sempre destacada, pois a cidade é direito de todos e mais importante que parecer ser é efetivamente ser.

ao uso de materiais de baixa energia. A expressão Hightech/Lowtech foi utilizada por Dominique Gauzin-Müller - "Arquitetura sustentável: lowtech ou hightech?" em palestra proferida no Instituto de Arquitetos do Brasil/RJ, aos 14 de abril de 2011, sobre arquitetura ecológica e ao urbanismo sustentáveis. 
